\title{
Active fault databases: building a bridge between earthquake geologists and seismic hazard practitioners, the case of the QAFI v.3 database
}

\author{
Julián García-Mayordomo ${ }^{1,2}$, Raquel Martín-Banda ${ }^{1,2}$, Juan M. Insua-Arévalo ${ }^{2}$, José A. Álvarez-Gómez ${ }^{2}$, \\ José J. Martínez-Díaz ${ }^{2}$, and João Cabral ${ }^{3}$ \\ ${ }^{1}$ Instituto Geológico y Minero de España, 28003 Madrid, Spain \\ ${ }^{2}$ Department of Geodynamics, Geology Faculty, Complutense University, 28040 Madrid, Spain \\ ${ }^{3}$ Department of Geology, Science Faculty, Lisboa University, 179-016 Lisbon, Portugal
}

Correspondence to: Julián García-Mayordomo (julian.garcia@igme.es)

Received: 31 March 2017 - Discussion started: 18 April 2017

Revised: 7 July 2017 - Accepted: 14 July 2017 - Published: 30 August 2017

\begin{abstract}
Active fault databases are a very powerful and useful tool in seismic hazard assessment, particularly when singular faults are considered seismogenic sources. Active fault databases are also a very relevant source of information for earth scientists, earthquake engineers and even teachers or journalists. Hence, active fault databases should be updated and thoroughly reviewed on a regular basis in order to keep a standard quality and uniformed criteria. Desirably, active fault databases should somehow indicate the quality of the geological data and, particularly, the reliability attributed to crucial fault-seismic parameters, such as maximum magnitude and recurrence interval. In this paper we explain how we tackled these issues during the process of updating and reviewing the Quaternary Active Fault Database of Iberia (QAFI) to its current version 3. We devote particular attention to describing the scheme devised for classifying the quality and representativeness of the geological evidence of Quaternary activity and the accuracy of the slip rate estimation in the database. Subsequently, we use this information as input for a straightforward rating of the level of reliability of maximum magnitude and recurrence interval fault seismic parameters. We conclude that QAFI v.3 is a much better database than version 2 either for proper use in seismic hazard applications or as an informative source for non-specialized users. However, we already envision new improvements for a future update.
\end{abstract}

\section{Introduction}

Active fault databases are both an important managing tool for seismic hazard assessment as well as a convenient way of displaying and sharing scientific information of active faults. Knowledge about the location and activity degree of faults is crucial for seismic hazard and risk assessment, particularly for critical facilities such as nuclear power plants, radioactive waste storages and chemical plants, but also for planning anthropic activities that may involve changing the natural stress state in the crust: water reservoirs, underground gas storage, fracking, etc. The importance of active faults is a matter of concern in modern seismic code provisions, for example in Eurocode-8, in which official documents issued by competent national authorities are referred to for the identification of such faults (e.g. Eurocode-8: Part 5; CEN, 2004). Active fault databases are also key for tsunami hazard assessments (e.g. Álvarez-Gómez et al., 2011) as well as for early warning systems, which are largely based on precomputed tsunamigenic faulting scenarios derived from information of such databases (e.g. Gailler et al., 2013).

Since the Quaternary Active Faults Database of Iberia (QAFI v.2) was released in February 2012 (GarcíaMayordomo et al., 2012a), an increasing number of studies have made use of it. The most relevant use so far has been for the creation of the new seismic hazard map of Spain (IGNUPM, 2013), performed considering the foreseen adoption of Eurocode-8 throughout 2017. QAFI faults were considered to be complementary information for designing seismo- 
genic source-zones models, for estimating maximum magnitude distributions in each source zone as well as assigning the predominant rupture mechanism required for ground motion prediction equations (GMPEs) (García-Mayordomo et al., 2012b; García-Mayordomo, 2015).

However, the seismogenic model did not explicitly consider QAFI faults to be seismogenic sources. The National Seismic Hazard Map Committee considered that the information available at that time (ca. 2011) was not complete enough to homogenously cover all the territory, and that it was affected by large uncertainties that prevented its use for producing an official standard for the country. Besides, a number of tests showed that the most active faults in QAFI (e.g. Eastern Betic Shear Zone) had a lower impact on hazard when modelled as sources than a regular seismogenic-zone for the targeted return periods of the map (475 and 950 year) (García-Mayordomo et al., 2012c).

Interestingly, Rivas (2013) analysed the effect of considering QAFI faults as sources in depth for the same return periods and found that these faults were clearly controlling the spatial distribution and amplitude of hazard. The reason for this is found in the GMPE model used, which considered near-source effects (e.g. Campbell and Bozorgnia, 2013), remarkably increasing the hazard in the vicinity of the fault. Rivas (2013) also tested the application of a Brownian passage time renewal model for the Carboneras Fault, a major active fault belonging to the Eastern Betic Shear Zone. Following Rivas (2013) methodology, QAFI faults were modelled as sources to update the seismic hazard map of the region of Murcia (SE Spain), which was the basis for the design of the new civil protection plans for the region after the $M_{\mathrm{w}}=5.2$ Lorca 2011 earthquake (Benito et al., 2015).

Although QAFI is mostly used for seismic hazard calculations, as explained above, the database has also become a primary source of information for both researchers and journalists in the event of an earthquake in Spain. Reference to QAFI is increasing in the frame of engineering projects, a practice that is foreseen to be increased when the application of Eurocode-8 comes into force in Spain.

However, since QAFI v.2 was released it was known that the database presented important shortcomings for direct use in seismic hazard assessment (García-Mayordomo et al., 2012a, d). There was a strong urge to review and update the database in order to make it more complete, uniform and consistent, in such a way that it could provide guidance on the reliability of the seismic parameters of the faults, not just for seismic hazard practitioners but for non-specialist users as well. Fault-source characterization for hazard calculations demands the quality of the geological information on which seismic parameters are eventually derived to be somehow be rated.

This paper summarises the work carried out to update QAFI to v.3, aiming to improve completeness and homogenizing criteria and consistency across the database. Particular effort has been made to classify the quality of geologi- cal data in order to provide an objective reliability rating of crucial fault-seismic parameters: maximum magnitude and recurrence interval. As a result, QAFI v.3 is a much better database than version 2 , and more appropriate for use by seismic hazard analysts and earth scientists, and even by nonspecialized users such as engineers, teachers or journalists.

\section{Updating process to QAFI v.3}

\subsection{QAFI v.2 basic problems}

It was well known since QAFI v.2 was released that the database had some problems of completeness and uniformity (García-Mayordomo et al., 2012a, d), even though at that time QAFI v.2 was the most informative source of active faulting in Iberia. On one hand, some important sources of information had not been analysed in detail (e.g. Neotectonic Map of Spain: IGME and ENRESA, 1998; other regional neotectonic maps: ITGE, 1991) and on the other hand, some records were not properly compiled or not all possible data had been adequately compiled. That was the case for some crucial database fields such as the description of evidence of Quaternary activity, fault geometry parameters (maximum depth, dip) and slip rates. Additionally, the variability range or error of important parameters (e.g. slip rate) was not quoted and indicated in many cases. Hence, it was clear that a thorough revision of existing but not yet compiled data, as well as a revision of the original sources of information for already compiled data, was much needed.

Uniformity of criteria is of paramount importance in active fault databases, especially when these are open to general and not specialized users. The database fields' maximum magnitudes and recurrence intervals, which are crucial in seismic hazard applications, were not always calculated following the same criteria and methods in QAFI v.2. The estimation of the maximum magnitude was calculated using a variety of empirical relationships, which in some cases offered very different results, as was the case, for example, for Wells and Coppersmith (1994) compared to the pre-instrumental equation of Stirling et al. (2002). Additionally, the independent variable used in these equations was also different in many cases, for example the length of surface rupture compared to the rupture area. The consideration of equations derived from subsets considering the style of faulting compared to the overall dataset was also a common difference for a number of records. In a similar way, the estimation of the recurrence interval was approached in different ways, and when information on uncertainty was available, it was not always possible to discern with confidence how it had been calculated.

A main issue that a seismic hazard analyst has to face eventually is quoting the reliability of different, but plausible hypotheses regarding geological data and seismic parameters of fault sources. The common approach to tackling this prob- 


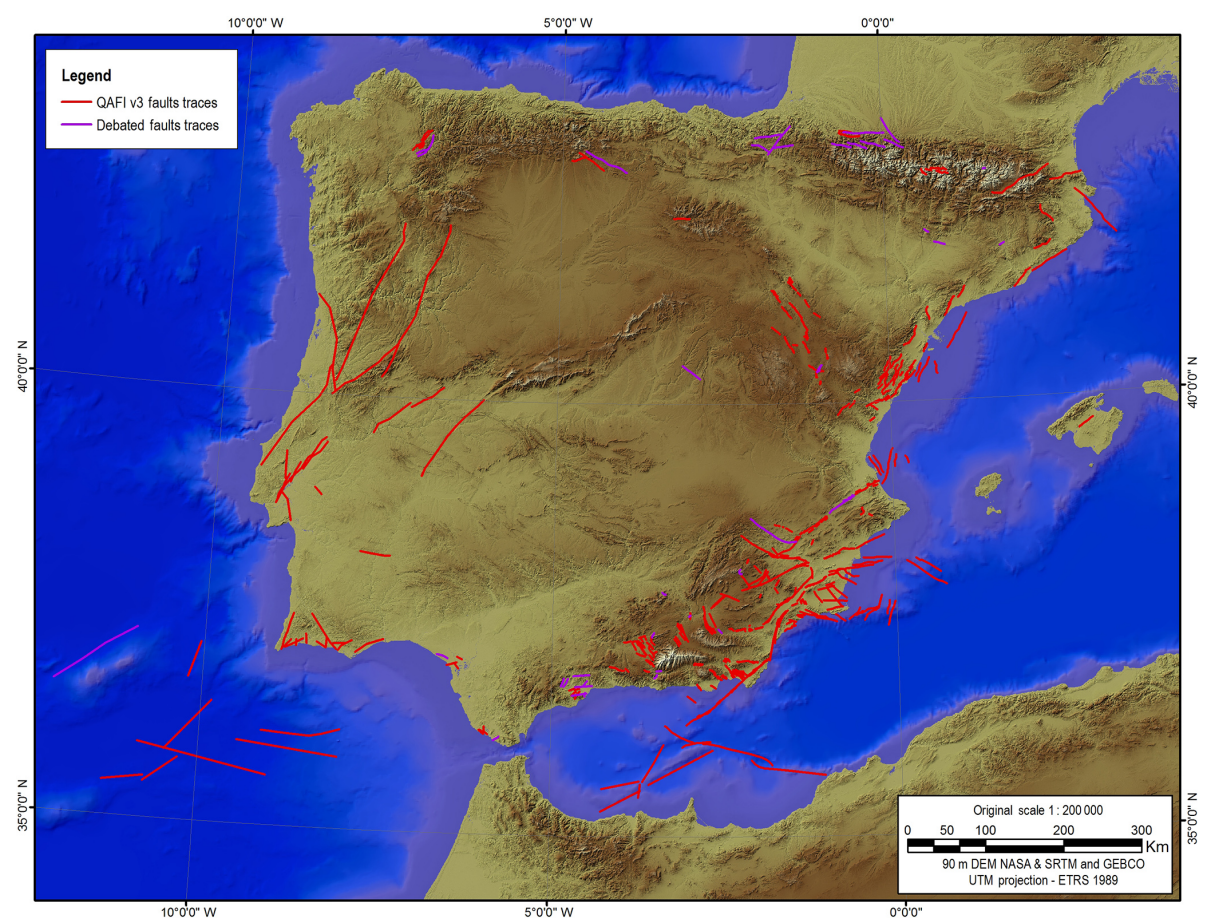

Figure 1. Representation of the QAFI v.3 and Debated Faults databases. Users can query both databases online in http://info.igme.es/qafi/.

lem - elegantly called epistemic uncertainty - is to follow a logic tree procedure in which each of the branches represent different alternatives on which the analyst expresses his/her confidence by assigning particular weights. This procedure may become a difficult issue, particularly if the hazard analyst is not acquainted with the active tectonics of the territory under study or simply because they are not specialized in earthquake geology. Hence, it was envisioned that an obvious improvement in a future update of QAFI would consist of devising a system for classifying the reliability of fault seismic parameters, not just for hazard analysts but also for any other potential users (e.g. researchers, engineers, journalists, teachers, civil officers).

\subsection{Revision and updating}

QAFI v.3 was released in September 2015, after thorough revision, updating and adding of new data (Fig. 1). For a complete description of the fields that form the database the reader is referred to QAFI v.3 documentation and guide available on the web (IGME, 2015). The new version contains 299 records, $30 \%$ more than the old v.2. New records come fundamentally after reviewing the complementary material and reports that lead to the publication of the neotectonic maps of Spain (IGME and ENRESA, 1998) and Murcia Region (ITGE, 1991). It is worth mentioning that only those faults that were clearly named and identified in the reports and the accompanying maps were considered for incorporation into the database. Faults failing to meet these crite- ria were not included as a record in the database, although their cartographic traces can be shown together with QAFI faults in the website. Additional sources of new information were thesis dissertations (e.g. Simón, 1984), the special issue on Active Tectonics in Iberia published in the Journal of Iberian Geology (Martínez-Diaz et al., 2012), the proceedings of the Iberfault 2014 meeting (Álvarez-Gómez and Martín-González, 2014) and a number of papers published in earth science journals since 2012.

QAFI v.2 records were revised one by one, verifying the original sources of information referred to by the original compilers and, in many cases, contacting them to help the compiling process or just to get their approval on the update of the data compilation. We wanted to keep the same approach as used in QAFI v.2, that whenever possible the main compiler should coincide with a major author on the fault, even though it generally makes the compilation process slower. Particular attention was paid to the database fields describing the evidence of Quaternary activity, age of last deformation, geometry and kinematics, and slip rate.

In some cases, the revision process led us to exclude certain faults from the final QAFI v.3 database. These faults were moved to a new database called "Debated Faults" (40 records) (Fig. 1). Debated faults are those that do not show either concluding evidence of Quaternary activity or evidence that is not yet published in a peer-reviewed journal. The Debated Faults database is also available to the public on the QAFI web site (IGME, 2015). 
A special effort was made to produce a best estimation of net slip rates (slip along displacement vector) and its uncertainty. In many cases, slip rates were not estimated in the original publications and had to be calculated ad hoc searching for valuable data included in them. This calculation was done transparently, clearly detailing the data and approach used in a memo field associated with the estimation called "brief comment". In some cases there was not enough information for such an estimation and so slip rates were estimated by expert judgement, usually by comparison to similar faults in the area. In spite of the effort, $22 \%$ of the records still lack a slip rate estimation.

The variability/error field associated with slip rate in QAFI v.3 may show either the range of variation of the estimation based on uncertainties in geological assumptions or some sort of statistical error based on the randomness of the measurements. An example of the former would be a slip rate determination based on assumptions of the age of a nondated marker, which could lead to two extreme values; this is usually quoted as a range (e.g. $0.5-1.0 \mathrm{~m} \mathrm{kyr}^{-1}$ ). For the latter, consider for example a variability estimation based on the standard deviation of radiometric dates given by a laboratory; this is usually quoted in QAFI v.3 as an error (e.g. $\left.\pm 0.08 \mathrm{~m} \mathrm{kyr}^{-1}\right)$.

Finally, the revision and updating process included verifying the cartographic traces of the faults against the original sources of information, georeferencing all them to the same date (ETRS89), and double-checking for a good match with associated landforms as observed in satellite imagery and DTMs. For those faults compiled from the Neotectonic Map of Spain project georeferencing had to be done by hand as the original source is made up of a composite of different paper sheets, none of them properly georeferenced.

\subsection{Criteria homogenization}

In particular we refer here to the method considered for calculating maximum magnitudes and associated recurrence intervals. If an active fault database is going to include these parameters, then it is important that they are calculated in a consistent, homogenous way, allowing direct comparison between records. It is up to the hazard analysts to eventually either assume these values or consider different ones for their own purposes. However, for non-specialized users, such as engineers or journalists, it is important that these critical values are consistent and comparable across the database. In QAFI v.3 maximum magnitude and recurrence interval have been calculated consistently in the same way all through the database, except for the latter, for which a few records (\#12) had conclusive palaeoseismic data while for \#111 (37\%) the available data was simply not enough to draw an estimation. In the case that an estimation for any of these data was already published, we kept and referenced it in the accompanying brief comment memo field.
Maximum magnitude is estimated in QAFI v.3 considering the value quoted in the field "length" of the fault, and making use of Stirling et al. (2002) regression equation of moment magnitude on the surface rupture length derived from an updated instrumental dataset after Wells and Coppersmith (1994). Length is a field that is always accounted for in every record of QAFI v.3 and one of the fields that can be more accurately estimated, compared to rupture area, for instance, for which uncertainties in the variation of dip with depth as well as the maximum brittle depth of the fault itself strongly affect the result. Hence, length was chosen as the independent variable for obtaining moment magnitude considering an equation based on empirical data.

The choice of Stirling et al. (2002) took place along with several working meetings devoted to the intensity-tomoment magnitude conversion equation $\left(I-M_{\mathrm{w}}\right)$ in the frame of the preparation of the Spanish National Hazard Map (IGN-UPM, 2013). In countries with a long historical earthquake record, such as Spain, this conversion is a crucial issue as it determines the maximum magnitude of the events in the catalogue. Desirably, these conversion equations have to provide outputs consistent not just with damage descriptions in buildings but also with known environmental effects, such as those described in the Environmental Seismic Intensity (ESI) scale (Michetti et al., 2007). For instance, in the ESI scale, surface-rupture earthquakes appear from intensity VIII onwards, so it would not be reasonable that pre-instrumental events with lower intensities could be converted to $M_{\mathrm{w}}>6.0$. An additional issue is the estimation of the upper bound of the Gutenberg-Richter distribution when characterizing seismogenic sources. In seismic hazard assessment practice this is usually done based on the maximum event recorded in the zone (e.g. adding to it 0.5 magnitude units), and desirably it should be consistent with the maximum $M_{\mathrm{w}}$ that could be derived from the active faults contained in the zone. Furthermore, for zones showing scarce seismicity, the estimation of maximum $M_{\mathrm{w}}$ from fault data may be the most reliable approach, if not the only one. Hence, a set of equations available at that time were tested against the outputs of the $I-M_{\mathrm{w}}$ conversion equation (see García-Mayordomo, 2015 and references therein), and the only two available data on fault ruptures and historical earthquakes in Spain (e.g. 1884 Arenas del Rey and 1829 Torrevieja earthquakes, related to Ventas de Zafarraya and Bajo Segura Faults, respectively). It was found that the outcomes of the Stirling et al. (2002) equation were the most consistent. Nevertheless, for the faults located in the Gulf of Cádiz, where thick oceanic crust occur, maximum magnitudes may be much higher than predicted from that relationship. For these records the maximum magnitude brief comment memo field describes other alternatives and estimations cited in published literature.

The variability/error field for maximum magnitude in QAFI v.3 simply accounts for the standard deviation of expected $M_{\mathrm{w}}$ according to the Stirling et al. (2002) equation for 
the instrumental dataset. In those cases where uncertainty in length is significant, we use the brief comment memo field to explain and account for this issue in the magnitude estimation. For example, the Palomares fault (ES609), a 5-10 km wide $\mathrm{N}-\mathrm{S}$ shear zone that forms part of the Eastern Betic Shear Zone, is ca. $60 \mathrm{~km}$ long, although to estimate maximum magnitude in QAFI v. 3 we used $10 \mathrm{~km}$, which is the maximum length of single fault traces inside the shear zone. A hazard analyst may also consider plausible a multisegment rupture comprising $60 \mathrm{~km}$ and include this possibility as a branch in a logic tree scheme.

The recurrence interval in QAFI v.3 is estimated considering the maximum magnitude earthquake model (MEM) (Wesnousky, 1986). This model assumes that each fault or fault segment releases a seismic moment in just one maximum event that marks the end/beginning of a seismic cycle. The opposite model considers that the fault releases seismic moment by means of events of all sizes fitting an exponential distribution - i.e. a Gutenberg-Richter relationship. An intermediate model is the characteristic earthquake model (Schwartz and Coppersmith, 1984), in which the fault produces events of all sizes up to a certain maximum, above which the fault only produces maximum events (see Wesnousky, 1994). QAFI v.3 considers the MEM model since it is a simple and straightforward method that can be invoked by only considering geological data obtained from the field.

In considering the MEM, slip rate (SR) represents the average rate at which maximum earthquakes are released by the fault. Because these maximum earthquakes are all of a similar size, and so they were produced by a similar coseismic displacement $(D)$ on the fault plane, their average frequency (i.e. recurrence interval, RI) can be simply calculated as follows:

$\mathrm{RI}=\frac{D}{\mathrm{SR}}$.

However, the parameter displacement $(D)$ of such a single maximum event is very difficult to specify, either from palaeoseismic studies or from empirical regressions on the length of the surface rupture, which so far show tremendous uncertainty. In QAFI v.3 we calculated recurrence intervals considering the ratio between the seismic moment released from a maximum event and the seismic moment rate defined by slip rate. Maximum seismic moment $\left(M_{0}\right)$ is calculated from maximum moment magnitude $\left(M_{\mathrm{w}}\right)$ using the Hanks and Kanamori (1979) equation:

$M_{\mathrm{w}}=\frac{2}{3} \log M_{0} 10.7$.

Seismic moment rate $\left(\dot{M}_{0}\right)$ is obtained using Aki's equation (Aki, 1966), substituting average fault displacement $(D)$ for slip rate:

$\dot{M}_{0}=A \cdot \mathrm{SR} \cdot \mu$.
Recurrence interval (RI) is eventually calculated as follows:

$\mathrm{RI}=\frac{M_{0}}{\dot{M}_{0}}=\frac{10^{1.5 M_{\mathrm{w}}+16.05}}{A \cdot \mathrm{SR} \cdot \mu}$.

This procedure means that $M_{\mathrm{w}}$ is not independently derived, but empirically obtained from the length of the fault, which is a variable included twice when calculating rupture area in the seismic moment equation.

The recurrence interval field in QAFI v.3 accounts for a best estimation, which could result from considering either a preferred value of slip rate or an average slip rate. The variability/error is given as a range, bounded by the maximum and minimum values that result from accounting for the standard deviation of maximum magnitude and the variability of slip rate (either as a range or as a deviation). As mentioned before, for a few records (\#12) the recurrence interval quoted in the database is the one originally published in journals, albeit the brief comment field still accounts for the recurrence interval as calculated with MEM for comparative purposes.

Finally, in order to be as informative as possible for nonspecialized users of the database, the brief comment field associated with recurrence interval includes a statement indicating that the recurrence interval of smaller but damaging earthquakes may be much shorter than that one for maximum events.

\section{Assessing the quality of geological data and the reliability of seismic parameters}

One of the most outstanding differences of QAFI v. 3 from the previous version 2 is that the reliability of seismic parameters maximum magnitude and recurrence interval is classified according to the quality of the geological data on which they were derived. We believe this is very relevant progress considering that the use of this database is increasingly widening not just among earthquake science researchers or hazard analysts, but government agencies, industry and even mass media. There is an obvious need for any user to quickly grasp how reliable the data are for a particular fault of the database, and particularly sensitive are its maximum magnitude and recurrence interval. These two seismic parameters are fundamental for modelling a fault as a seismogenic source in seismic hazard analysis and, additionally, they are interpreted by the general public as indicators of the potential hazardousness of a fault.

In QAFI v.3 both maximum magnitude and recurrence interval are obtained directly or indirectly from geological data, as explained in the previous section. It becomes apparent that rating the reliability of these two parameters should be based on the quality and representativeness of the geological data from which they are eventually obtained. Desirably, the rating procedure should be as automatic and objective as possible, accounting for just the evidence and avoiding subjectiveness as much as possible. 
To account for the quality and representativeness of the geological data in QAFI v.3, we have added two new database fields named "strength of the Quaternary evidence" and "accuracy of the estimation" of slip rate. The former serves to eventually rate the reliability of maximum magnitude and the latter to rate recurrence interval.

When evaluating the reliability of maximum magnitude we refer here to the possibility that the fault could actually produce maximum events - i.e. an event that ruptures the surface for a similar extent to its measured length. We are not evaluating the credibility of the actual value of the magnitude. QAFI v.3 rates the epistemic uncertainty of maximum magnitude, conversely to the aleatory uncertainty that results from the natural variability of the fault-rupture parameters or from the use of empirical equations. Hence, our reliability rating is based on whether there is evidence that the fault has produced such events that geologists are able to recognize today in the field. In QAFI v.3 this is evaluated in the "strength of the Quaternary evidence" database field.

Rating of recurrence interval reliability is based both on the reliability rating of maximum magnitude and slip rate "accuracy of the determination". Slip rate is a key parameter in fault-source modelling, particularly in modelling earthquake frequency. In QAFI v.3 we calculate recurrence interval assuming a MEM (Wesnousky, 1986), as explained in the precedent section, and so the size of the maximum event is as crucial as slip rate for estimating the average frequency between maximum earthquakes. Furthermore, slip rate and maximum magnitude are also both crucial in other fault behaviour models, for example for determining the seismic activity rate of the fault in a Gutenberg-Richter-type model (e.g. Anderson and Luco, 1983; Youngs and Coppersmith, 1985). Hence, the reliability of the recurrence interval, or any other parameter related to fault-earthquake frequency, has to be considered jointly with the reliability of maximum magnitude (previously rated considering the strength of the evidence) and the accuracy of the slip determination.

We shall now show how we account in QAFI v.3 for the database fields strength of the evidence and accuracy of the slip rate determination, and subsequently explain the details of the procedure followed to rate the reliability of maximum magnitude and recurrence interval.

\subsection{Strength of the Quaternary activity evidence (SQE)}

This database field evaluates the quality, significance and representativeness of the information provided in the original bibliographic references from which data in the fields named "geomorphic evidence" and "age of the youngest deposit affected by the fault" are compiled (see García-Mayordomo et al., 2012a, d). Please note that we are not rating the quality of published work. The quality of the work is taken for granted, as it is assumed that it reached at least the minimum standards of the journal where the information was published at the time. What is evaluated here are the scale, methods, and detail of the observations that support the Quaternary activity evidence of the fault. This process was performed record by record once the compiling of new data was finished, and based on the experience gained after the revision of the entire database (see section on updating QAFI).

Strength of the Quaternary Evidence (SQE) is classified in three increasing levels of accumulated evidence: $\mathrm{C}_{\mathrm{SQE}}$, $\mathrm{B}_{\mathrm{SQE}}$ and $\mathrm{A}_{\mathrm{SQE}}$. Differentiation among classes is based on the scale of the observations and detail involved in obtaining the observations. Table 1 summarizes typical observations, scale and methods that usually characterize the available information at each level of evidence. Note that the classes denote accumulated evidence and increasingly stronger evidence. It is convenient to highlight that we are not evaluating the degree of activity of the fault here, but the significance of the evidence of activity in Quaternary times.

Class $\mathrm{C}_{\mathrm{SQE}}$ encompasses the less significant evidence. This is inferred from regional-scale observations of the fault trace, from interpretations of general geological maps or broad range geophysical methods to digital terrain models (DTM) (Table 1). At this level, there is usually a lack of field work focused on demonstrating inferred evidence, or the detail of the field work has not proved conclusive so far. Geochronology is usually only known in broad relative terms as Quaternary or in terms of the different stages of the Quaternary Period (Upper Pleistocene, etc.). Similarly, Quaternary landforms or deposits are mapped in broad, generic units: terraces, alluvial fans, etc.). Numeric dating of certain deposits is usually lacking or they are very scarce.

Class $\mathrm{B}_{\mathrm{SQE}}$ assigns faults that, having class $\mathrm{C}_{\mathrm{SQE}}$ evidence, also have additional observations from larger-scale works, and usually some field work. Quaternary geochronology is better constrained, although numeric dating of relevant stratigraphic units may still be lacking. The arrangement of Quaternary units is known more precisely and there is a differentiation of phases or stages inside generic landforms (e.g. differentiation between generations of alluvial fans or fluvial terraces) (Table 1).

Class $A_{\mathrm{SQE}}$ faults are those that have class $\mathrm{B}_{\mathrm{SQE}}$ (and $\mathrm{C}_{\mathrm{SQE}}$ ) evidence, as well as conclusive observations obtained from field work. In general, Level ASQE evidence is gained after intensive work at the office (e.g. photointerpretation, DTM analysis, ... ) followed by field work focused on confirming the evidence (e.g. trenching) (Table 1). Level $A_{S Q E}$ observations indicate the activity of the fault as a major controlling agent of Quaternary landforms or sedimentation, for example fault scarps offsetting Quaternary deposits. Numeric geochronology may still be lacking, but the refinement reached on the definition of the geomorphic units allows a reliable approximation to their age based on their relative spatial associations.

When rating the strength of the evidence, we should also consider its representativeness along the fault trace. In order to account for this issue, a plus sign $(+)$ is added to the assigned level of SQE of the fault (e.g. A+) when the evidence 
Table 1. Classification of the strength of the Quaternary activity evidence (SQE) of a fault in three levels of increasing significance, based on the scale of the available observations, type of data and methods used. The classification is not intended to be exhaustive but to furnish the approach and criteria used in QAFI v.3. See text for further information.

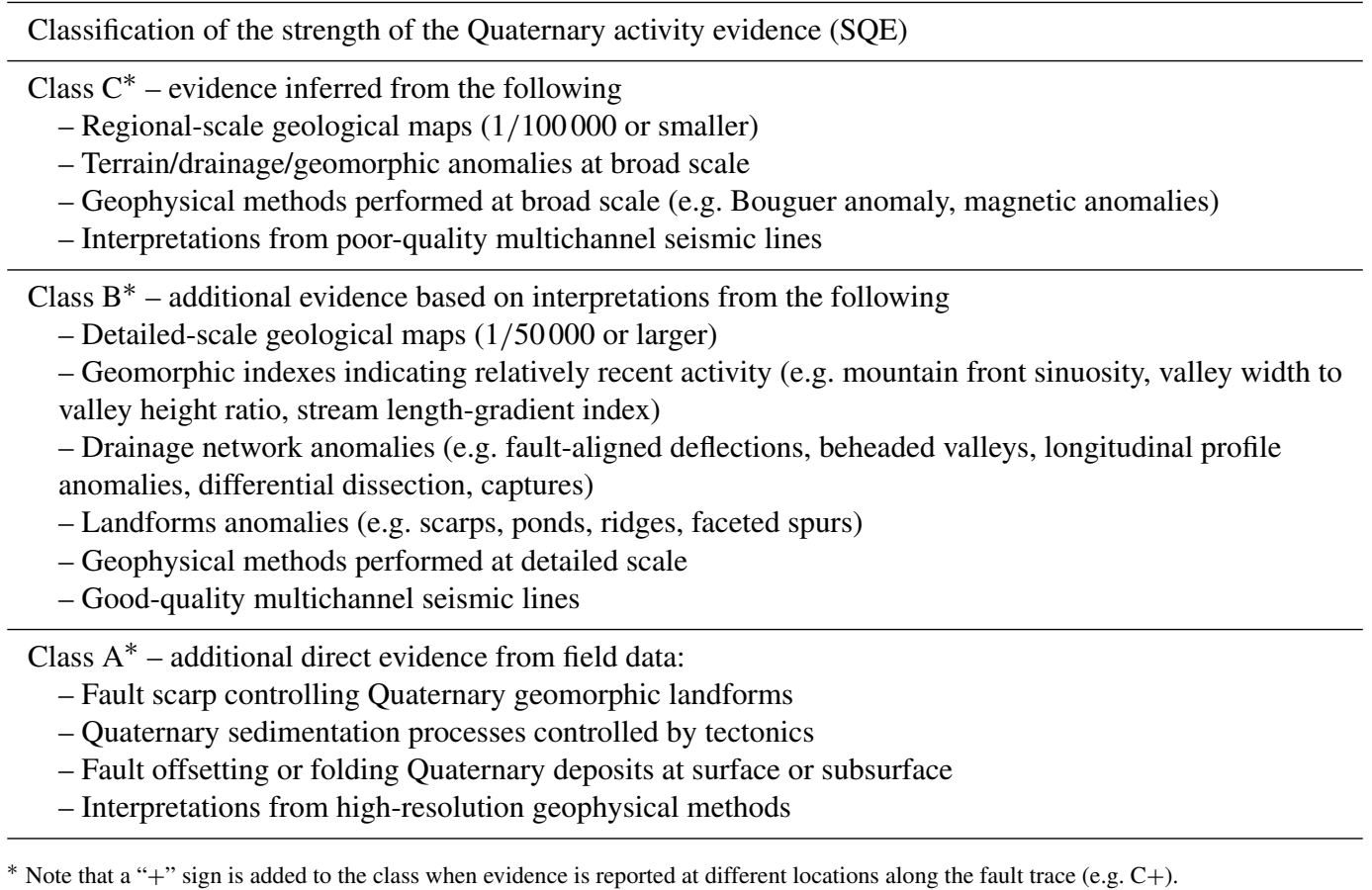

is consistently reported at different locations. However, this is a difficult issue to evaluate as the evidence of Quaternary activity of a fault may vary along its trace for very different reasons in addition to its activity degree. For example, it could be due to natural erosion/sedimentation processes, frequently in relation to anthropogenic activities, that may have blurred the evidence at some sections and thus biased available studies relative to other parts of the fault.

Distribution of SQE in the QAFI v.3 database shows that the majority of the records belong to class B $(39 \%$, \#101), followed closely by classes A $(32 \%, \# 83)$ and C (28\%, \#73) (Fig. 2). Note that this distribution does not account for 42 records that were not evaluated, all of them located in Portuguese territory. Interestingly, practically all the records that show a + sign in their SQE belong to class A. This situation may suggest that interpretations on the activity of a fault are often based on single location data; however reasonable that statement seems, we cannot reject that it may be an artificial bias from the evaluation process, as the effort was more focused on level A records.

\subsection{Accuracy of the slip rate estimation (ASR)}

This database field rates an estimation of the net slip rate of a fault on the basis of the accuracy of the parameters involved in its calculation, particularly displacement and age. The slip rate estimation may come from original research published in a journal or may be produced ad hoc as part of the revision

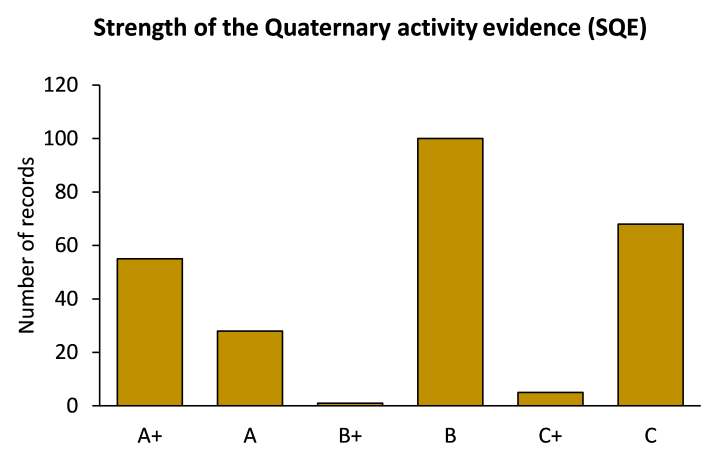

Figure 2. Distribution of level classes of strength of the Quaternary activity evidence (SQE) in QAFI v.3 database. See text for further details.

and updating process performed in QAFI (see previous section) from data either published in original publications or estimated by expert judgment. Accuracy of the slip rate estimation (ASR) differentiates among three increasing levels of accuracy: $\mathrm{C}_{\mathrm{ASR}}, \mathrm{B}_{\mathrm{ASR}}$ and $\mathrm{A}_{\mathrm{ASR}}$.

Class $\mathrm{C}_{\mathrm{ASR}}$ corresponds to a slip rate estimation based on the displacement of a marker measured from the interpretation of large-scale cartography or DTMs, while age control of the marker is assumed to correspond to generic Quaternary, Plio-Quaternary or the different stages that form the Quaternary Period (e.g. 125 ka Upper Pleistocene). Class $\mathrm{C}_{\mathrm{ASR}}$ slip 
rates are broad approximations that usually lack direct observations of the slip vector and dip of the fault, and it may be assumed from generic considerations on the general kinematics of the fault (e.g. a rake of $-90^{\circ}$ for a $60^{\circ}$ dip normal fault). Furthermore, in many cases slip rates are just assumed from comparison with similar faults in the region. The uncertainty of the estimation is very large and strongly depends on the broad controlling age considered.

Class $\mathrm{B}_{\mathrm{ASR}}$ corresponds to an estimation where one of the basic parameters, displacement or age, is well constrained. Displacement of the marker may be measured from the interpretation of large-scale cartography after some field work and age may be controlled by numeric dating of the marker or by association with similar stratigraphic units dated in the area. The slip vector of the fault and/or its dip are also better constrained than in class $\mathrm{C}_{\mathrm{ASR}}$. A net slip rate is usually estimated in addition to the vertical/horizontal components. Uncertainties can still be very large, but the range of maximum and minimum values is better constrained than in class $\mathrm{C}_{\mathrm{ASR}}$ estimations. Very often contrasting slip rate values are obtained when considering different hypothesis on the displacement and age of the marker.

Class $\mathrm{A}_{\mathrm{ASR}}$ describes slip rate estimations for which both displacement and age control are constrained by measurements at outcrop scale and age obtained from numeric dating methods or inferred from them. There is also a good knowledge on the true slip-vector and dip of the fault and, accordingly, net slip rate values are usually produced in the publications. Uncertainties in the estimation still can be large, but conversely to classes $\mathrm{C}_{\mathrm{ASR}}$ or $\mathrm{B}_{\mathrm{ASR}}$, these depend largely on the accuracy of the dating results and their interpretation in relation to the true age of the marker. Uncertainties are usually quoted as standard deviations or by similar statistical parameters (e.g. mean error). Age and displacement are clearly stated in the original publication in such a way that any reader could calculate exactly the same values. Typically, there is a discussion on the variation of the slip rate of the fault along different periods of activity.

Most of the slip rates in QAFI v.3 have been rated as class $\mathrm{C}_{\mathrm{ASR}}\left(58 \%\right.$, \#150), distantly followed by classes $\mathrm{B}_{\mathrm{ASR}}$ $(10 \%, \# 25)$ and $A_{A S R}(6 \%, \# 15)$ (Fig. 3). As in the previous section, 42 records belonging to faults located in Portuguese territory were not included in this analysis. For a significant fraction of the dataset $(26 \%$, \#67) rating slip rate is not possible simply because such an estimation is not available, not even in terms of "expert judgment". The accuracy in the determination of slip rates has varied considerably in the last 10 years of active tectonics research in Spain. The younger the paper, the higher the effort in obtaining an accurate estimation of slip rate, reflecting clearly the increasing interest of Spanish geologists in seismic hazard practice.

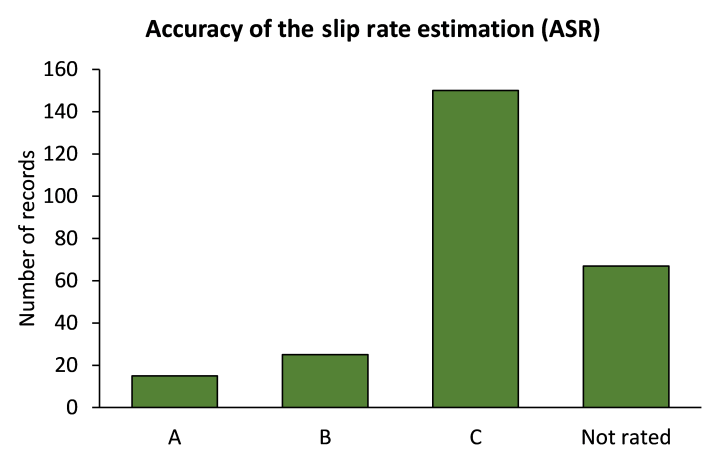

Figure 3. Distribution of classes of accuracy of the slip rate estimation (ASR) in QAFI v.3 database. See text for further details.

\subsection{Reliability of maximum magnitude (RMM)}

The reliability level assigned to a maximum magnitude estimation for an active fault should be based on the quality and representativeness of the geological information from which the estimation was eventually obtained (see the introduction of the section). However, for hazard analysts who are not particularly specialized in earthquake geology, this is not an apparent issue and sometimes neither is it for specialized ones, as analysing and evaluating geological data is usually complex and time consuming. Therefore, an objective indication of the reliability level of a maximum magnitude estimation should be a practical and desirable output in any active fault database.

We propose here that the reliability of maximum magnitude should be determined based upon the SQE (Strength of the Quaternary activity Evidence) classes defined for QAFI v.3 (Fig. 4). As explained in the introduction of the section, here reliability is a concept linked to epistemic uncertainty (i.e. whether it is plausible that a particular fault could produce a maximum event) rather than to aleatory uncertainty, with regards to the value of the magnitude associated with such an event. Regardless, a reliable estimation of maximum magnitude should always be accompanied by a discussion on the sources of uncertainty and its impact on the expected value. Additionally, such a reliable estimation should be reached by a reader just considering the data and information provided in the paper. QAFI v.3 thus defines a new database field called "reliability of maximum magnitude" (RMM), which accounts for four levels of increasing reliability: $\mathrm{D}_{\mathrm{RMM}}, \mathrm{C}_{\mathrm{RMM}}, \mathrm{B}_{\mathrm{RMM}}$ and $\mathrm{A}_{\mathrm{RMM}}$. These levels are also named speculative, poorly reliable, reliable, and highly reliable.

A highly reliable level ( $\left.A_{M M}\right)$ is assigned only when the $\mathrm{SQE}$ of the fault has been rated $\mathrm{A}^{+}$- i.e. the Quaternary activity of the fault is clearly evidenced and consistent along its trace. Hence, the occurrence of past earthquakes that ruptured all the fault or segment trace is very plausible (Fig. 4). An $A_{M M}$ level is usually based on published information that discusses possible segmentation of the fault based on 


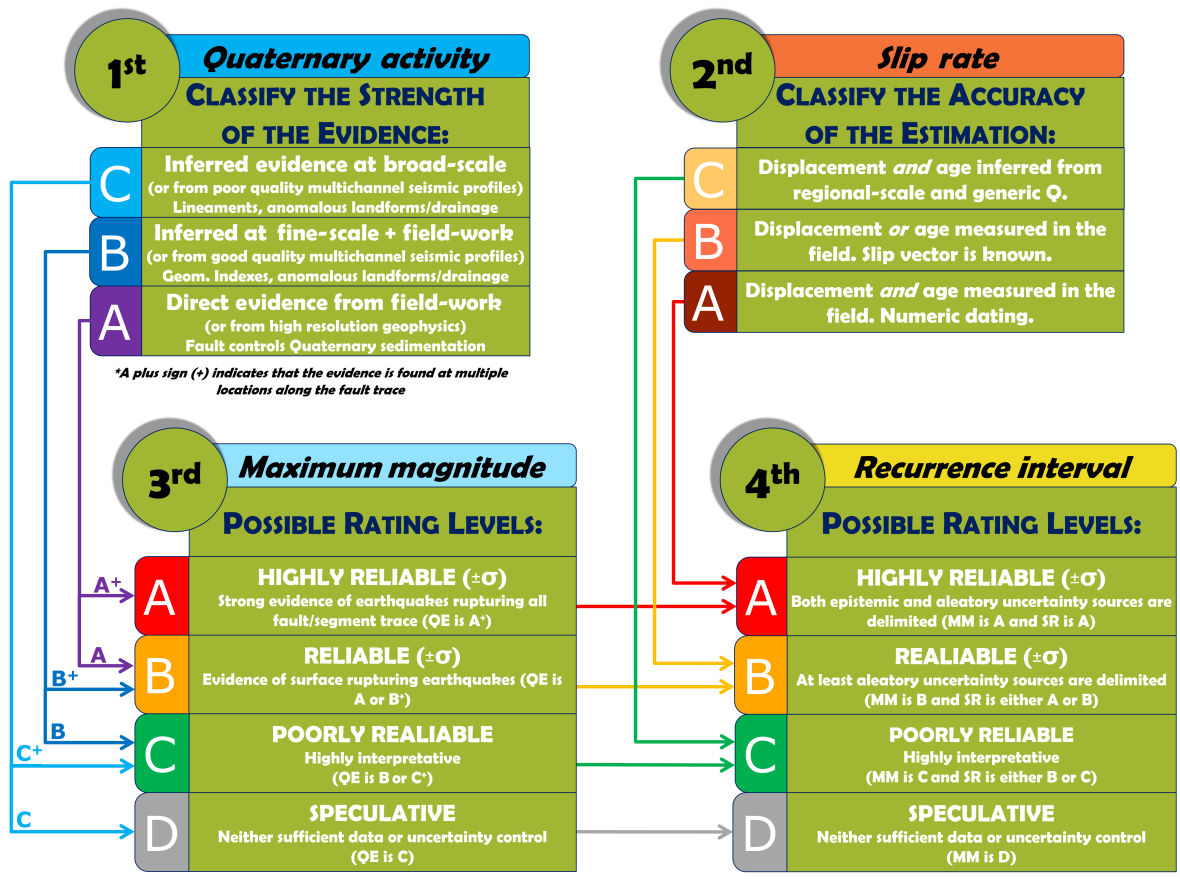

Figure 4. Diagram summarizing the scheme followed in QAFI v.3 for rating the reliability of maximum magnitude (RMM) and recurrence interval (RRI) on the basis of the strength of the Quaternary activity evidence (SQE) and the accuracy of the slip rate estimation (ASR). First, the SQE of the fault is classified based on the detail of the available published observations in three increasing levels of accumulated evidence, varying from $\mathrm{C}$ (weak) to A (very strong). A plus sign (+) is assigned when the observations can be extrapolated with confidence all along the fault trace. Second, the ASR is classified based on the accuracy of the information used for its determination, varying from $\mathrm{C}$ (rough) to A (accurate). Third, RMM is obtained from SQE class, varying from A (highly reliable) to D (speculative). Fourth, RRI is obtained from both RMM and ASR. The resulting RRI would never be higher than the rated level for RMM, yet it could be lower depending on the ASR (these relationships are not shown on the diagram for the sake of simplicity). See text and Table 1 for a more extensive explanation.

slip rate variations, geometry variations or other related issues. Furthermore, the uncertainty in the maximum magnitude estimation procedure is usually analysed in the publication considering different sources such as variation of rupture parameters (length, width, depth), variation of displacement per event at outcrop scale, variation from the use of different empirical equations according to type of faulting or tectonic environment and the nature of the crust. Eventually, the authors may prefer a particular maximum magnitude value to another, this choice always being clearly explained in the paper in such a way that a reader could calculate the same figure and its associated uncertainty.

$A B_{R M M}$ level (reliable) is assigned when the SQE of the fault is either $\mathrm{A}$ or $\mathrm{B}^{+}$(Fig. 4). For these faults there is usually a lack of palaeoseismic studies, but the geological information is good enough for analysing uncertainties from the variation of rupture parameters, as well as for the variation of style of faulting or tectonic regimen according to different scaling relationships. A general reader is usually able to calculate the same maximum magnitude MM value as proposed by the authors based on the data stated in the paper.

$\mathrm{A} \mathrm{C}_{\mathrm{RMM}}$ level (poorly reliable) comes from a fault with an SQE that is either B or C (Fig. 4). An additional lower level called speculative $\left(\mathrm{D}_{\mathrm{RMM}}\right)$ is considered for rating maximum magnitude estimations specifically derived from sources in which crucial data regarding to the calculation is missing and so it is impossible for a reader to reach a similar value without making speculative assumptions.

Approximately two-thirds of the records in QAFI v.3 database, excluding 42 records in Portugal, show a maximum magnitude estimation rated as poorly reliable $\left(\mathrm{C}_{\mathrm{RMM}}\right)$ or speculative ( $\left.D_{\text {RMM }}\right)(41$ and $26 \%$, respectively) (Fig. 5). The other third are very reliable $\left(A_{R M M}\right)$ or just reliable $\left(B_{R M M}\right)$ (21 and $11 \%$, respectively). This situation highlights the importance of being prudent when using these data and trying not to jump to conclusions, without first checking reliability.

\subsection{Reliability of recurrence interval (RRI)}

Rating the reliability of the recurrence interval of maximum events of an active fault should be based on the two basic parameters that are involved in such an estimation: maximum magnitude and slip rate (see the introduction of the section). Therefore, here we proposed to evaluate the reliability of a recurrence interval estimation after rating the level of reliability of maximum magnitude (RMM) and the accu- 
Reliability of maximum magnitude (RMM)

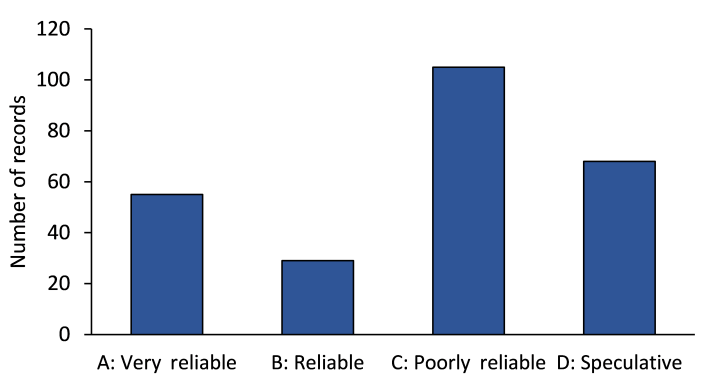

Figure 5. Distribution of rating levels for the database field reliability of the maximum magnitude estimation (RMM) in QAFI v.3 database. See text for explanations.

racy of the slip rate determination (ASR) (Fig. 4). Similarly to RMM, an estimation of recurrence interval should always include an uncertainty analysis and its impact.

QAFI v.3 defines a database field called reliability of recurrence interval (RRI), which accounts for four levels of increasing reliability: $\mathrm{D}_{\mathrm{RRI}}, \mathrm{C}_{\mathrm{RRI}}, \mathrm{B}_{\mathrm{RRI}}$ and $\mathrm{A}_{\mathrm{RRI}}$. Similarly to RMM these levels are also named speculative, poorly reliable, reliable, and highly reliable. Although QAFI v.3 has chosen to show recurrence interval calculated following the MEM (see introduction), the rating levels hereby defined for recurrence interval can be easily adapted to rate the reliability of earthquake frequency parameters in any other model of fault behaviour that relies on maximum seismic moment and seismic moment rate.

A highly reliable level $\left(A_{R R I}\right)$ is attributed only when both RMM and ASR have the highest rating (Fig. 4). Published information on a fault with a $A_{R R I}$ level usually thoroughly discuss uncertainties both from epistemic and aleatory sources. The former at least accounts for the possibility that maximum events happened clustered in time and for the consistency between the size of maximum events derived from single-event displacements in the field and the maximum rupture dimensions of the fault. The source of aleatory uncertainty accounts for variations in the number of possible events in a time period, which also has an associated error in relation to the numeric dating results and their interpretation. The authors of the information may prefer a particular recurrence interval value to another, but this is always clearly stated in the paper so an external reviewer could reach the same value, similarly to what is explained in the preceding section for RMM. Uncertainty is usually quoted as a range (maximum to minimum possible values) or using a statistical parameter as standard deviation or mean average error.

Level $B_{R R I}$ (reliable) results from a record in which RMM and ASR have been rated B and A or B, respectively (Fig. 4). An analysis of the aleatory sources of uncertainty is usually included in the published information and the uncertainty is quoted either as a range or an error. A poorly re-

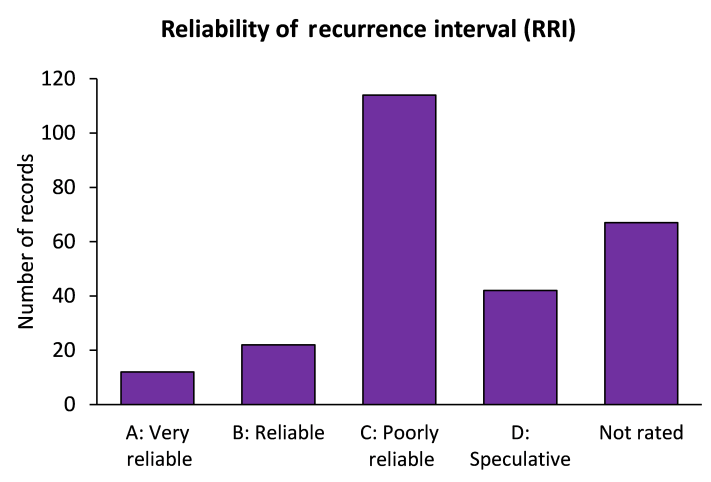

Figure 6. Distribution of rating levels for the database field reliability of recurrence interval (RRI) in QAFI v.3 database. See text for explanations.

liable level $\left(\mathrm{C}_{\mathrm{RRI}}\right)$ is assigned when $\mathrm{RMM}$ has been rated $\mathrm{C}$ and ASR rated B or C (Fig. 4). This level rates the recurrence interval estimation as highly interpretative. The information indicates tentative bounds for the range of variation of the parameter. Finally, an additional $\mathrm{D}_{\mathrm{RRI}}$ level (speculative) is considered to rate recurrence interval estimations derived from information sources that lack sufficient data to pursue the procedure followed to reach the estimation and/or when any source of uncertainty is considered.

More than half of QAFI v.3 records show a recurrence interval estimation rated as poorly reliable or speculative (44 and $16 \%$, respectively) (Fig. 6). Estimations rated as reliable or highly reliable sum up $14 \%$ of the total ( 9 and $5 \%$, respectively). A significant fraction (26\%) corresponds to records in which there was no available information on the slip rate and hence RRI could not be rated. Note that 42 records belonging to faults located in Portugal were not considered in the statistics. Estimations rated highly reliable (\#12) coincide with faults having specific palaeoseismic and active tectonic studies. Interestingly, these faults do not always coincide with the most active of the database but with the most studied.

\section{Summary and discussion}

Active fault databases are an important source of systematized knowledge, not just for hazard analysts and earthquake science researchers, but also for engineers following seismic regulations, journalists looking for information for articles, and even for common citizens. In this context, active fault databases should be updated on a regular basis, show uniformity of criteria and somehow indicate the quality of the raw information and the reliability of seismic hazard parameters derived from it. By updating QAFI to version 3 we have tried to closely follow those assertions.

QAFI v.3 is a more complete, homogenous and better quality database than QAFI v.2, the previous version released 
in February 2012. QAFI v.3 contains 299 records, which is $30 \%$ more than v.2. All of them have been revised aimed at reaching a minimum quality and homogenous standard for the entire database. It was found that 40 records did not actually show concluding evidence of Quaternary activity or were not yet published and so were excluded from QAFI v.3 and stored in a newly developed database named "Debated Faults". This database can be downloaded from the QAFI web site (IGME, 2015) and displayed online together with QAFI faults.

The seismic parameters maximum magnitude and recurrence interval have been calculated uniformly throughout QAFI v.3. For the former we used the length of the fault and Stirling et al. (2002) regression on $M_{\mathrm{W}}$ derived from an updated instrumental dataset based on Wells and Coppersmith (1994). Our primary interest was to produce $M_{\mathrm{w}}$ estimations comparable from fault to fault across the database, using a well-controlled parameter (length) and an equation that have shown consistent outputs with the intensity-to- $M_{\mathrm{w}}$ relationship used in the official seismic hazard map of Spain (IGN-UPM, 2013). We do not advocate for the use of either that parameter or that empirical equation for calculating fault-related magnitudes in Iberia. The issue is left to be solved by a seismic hazard analyst, depending on the scope and scale of a particular project. For instance, we warn that for maximum magnitudes of the faults located in the thick oceanic crust of the Gulf of Cádiz an alternative approach should be considered. The recurrence interval is calculated, assuming the maximum magnitude earthquake model (Wesnousky, 1986) from the ratio between maximum seismic moment (from maximum $M_{\mathrm{w}}$ ) and seismic moment rate (from slip rate). Similarly, we do not advocate that this model better fits the seismogenic behaviour of Iberian faults, but rather that it is a model completely based on geological data and convenient for comparing among faults across the database.

Although final decisions on the expected values and variation of maximum magnitude or recurrence interval are up to the hazard analyst, QAFI v.3 presents a scheme for rating the reliability of these two crucial parameters in a straightforward and objective way based on the quality and representativeness of the available geological information. Reliability is graded in four levels: speculative (D), poorly reliable (C), reliable (B) and highly reliable (A) (Fig. 3). Reliability levels are assigned straightforwardly depending on the qualification obtained in two extra fields that evaluate the geological data: strength of the Quaternary activity evidence (SQE) and accuracy of the slip rate estimation (ASR). We believe that this scheme is very valuable for any potential user of the database. Hazard analysts can use it to support decision making when building logic trees or managing epistemic uncertainty in general. Furthermore, general users can use it to quickly check the quality of the available information, detect knowledge gaps and learn about to what extent results can be trusted.
Two important shortcomings in QAFI v.3 are the large number of records for which we have no estimation of slip rate $(26 \%)$, and the need to thoroughly review $42(14 \%)$ records belonging to faults located in Portugal. Regarding the former, part of the problem derives from our interest in keeping the v. 2 concept in the sense that whenever possible the compiler is also the major author of the fault. This point sometimes leads to compilations that do not make the best use of the available data, depending on the willingness of the author and his/her support of the QAFI project. In other cases, it is because there is simply a lack of sufficient data. Nevertheless, a forthcoming version of the database should address this problem in such a way that every record shows a slip rate estimation, even though many of them will be estimated as expert judgment based on slip rates of similar faults in the vicinity or from geodetic data. Additionally, extra effort has to be made to quote slip rate uncertainties, and doing it whenever possible following the same criteria and procedure across the database. Finally, the available information about Quaternary faults in Portugal has not yet been thoroughly analysed. This would be addressed in a future QAFI version. Additionally, in the case of Spain it would be convenient to explore sources of information older that the Neotectonic Map (IGME and ENRESA, 1998), taking advantage of the fact that all Spanish territory has been mapped geologically at 1:50000 scale (MAGNA National project: IGME, 2017).

The process of reviewing and updating QAFI has been an opportunity to learn about the evolution of active tectonic studies in Spain for the last 30 years. It has also given us an opportunity to detect shortcomings as well as to propose improvements. Before ca. 1990 most of the efforts were devoted to Neogene sediments, and most of the studies use the name "neotectonic" to refer to tectonic deformations from the Upper Miocene to the present. From a tectonic point of view the Quaternary was not yet a matter of proper study. Later, studies focused on tectonics affecting Quaternary sediments and geomorphic features began to emerge. Initially these studies were qualitative in character, mostly devoted to illustrating the evidence. As the interest of including geological data in hazard analysis practice in Spain is consolidated, these studies gradually become more quantitative. A greater deal of work is then dedicated to slip rate estimation and geochronology dating of the most affected recent sediments. In current times, practically all of the papers published on active tectonics in Spain attempt to quantify fault-geometry and -kinematic parameters, potential maximum magnitudes and recurrence intervals. It should be warned that in some cases major interpretations are based on very few measurements, on data that show great variability (e.g. numeric dating), or they are just based on observations at single locations (e.g. a trench). This situation brings up recommendations for future active tectonic studies in Spain: identifying the sources of uncertainty and quantifying them in a standard way. 


\section{Conclusion}

QAFI v.3 is a much better source of information for seismic hazard analysts of active faults in Iberia than version 2. The new version is more complete, more uniform and consistent. Furthermore, QAFI v.3 serves as a baseline for managing epistemic uncertainty in fault hazard analysis. The reliability of maximum magnitude and recurrence interval of faults is rated based on the quality and representativeness of the geological data from which these parameters are eventually derived. However, it is warned that the QAFI database is a regional-scope project, and hence it should not substitute further geological studies in any way that may be appropriate to be carried out for site-specific hazard analysis or localscale hazard mapping. QAFI database is updated roughly every 4 years and always after the celebration of the Iberian meetings on Active Faults and Palaeoseismology (e.g. IBERFAULT, 2014).

Data availability. The QAFI database can be accessed and downloaded at http://info.igme.es/qafi/ (IGME, 2015).

Competing interests. The authors declare that they have no conflict of interest.

Special issue statement. This article is part of the special issue "Linking faults to seismic hazard assessment in Europe". It is not associated with a conference.

Acknowledgements. The development of QAFI v.3 has been funded by SISMOGEN project (GESTEC 2279), from Instituto Geológico y Minero de España (IGME), and Civil Protection of the Region of Murcia. The authors are indebted to all the compilers of the database and particularly to J. M. Azañón and A. Azor (Granada University), A. Salazar (IGME), I. Rojas (Alicante University) and a few anonymous researchers, who gave their informed opinions on the QAFI v.3 classification scheme when presented at IBERFAULT 2014. Ángel Prieto (IGME) is particularly acknowledged for his great work producing QAFI's web page. The authors are very grateful for the comments and suggestions provided by N. Litchfield (GNS Science) and M. Cushing (IRNS) that led to an improved version of the manuscript.

Edited by: Bruno Pace

Reviewed by: Nicola Litchfield and Edward Marc Cushing

\section{References}

Aki, K.: Generation and propagation of $\mathrm{G}$ waves from the Niigata earthquake of June G 16, 1964. II. Estimation of earthquake movement, release energy, and stress-strain drop from waves spectrum, Bull. Earthq. Res. Inst., 44, 23-88, 1966.
Álvarez-Gómez, J. A. and Martín González, F. (Eds.): Una aproximación multidisciplinar al estudio de las fallas activas, los terremotos y el riesgo sísmico. Libro de resúmenes de la Segunda Reunión Ibérica sobre Fallas Activas y Paleosismología (IBERFAULT), Lorca (Murcia, España), 22-24 de Octubre de 2014, 266 pp., available at: http://www.iberfault.org/ images/docs/Iberfault2014_web.pdf (last access: 1 March 2017), 2014.

Álvarez-Gómez, J. A., Aniel-Quiroga, Í., González, M., Olabarrieta, M. and Carreño, E.: Scenarios for earthquake-generated tsunamis on a complex tectonic area of diffuse deformation and low velocity: The Alboran Sea, Western Mediterranean, Mar. Geol., 284, 55-73, 2011.

Anderson, J. G. and Luco, J. E.: Consequences of slip rate constants on earthquake recurrence relations, Bull. Seismol. Soc. Am., 73, 471-496, 1983.

Benito, B., Rivas, A., Pérez, M., Quirós, L. E., Barajas, S., GasparEscribano, J. M., and Hernández, R.: Servicio de actualización del análisis de riesgo sísmico (Rismur) en la Región de Murcia, Universidad Politécnica de Madrid - Protección Civil de la Región de Murcia, unpublished document, 88 pp., 2015.

Campbell, K. W. and Bozorgnia, Y.: NGA-West2 CampbellBozorgnia Ground Motion Model for the Horizontal Components of PGA, PGV, and 5\%-Damped Elastic PseudoAcceleration Response Spectra for Periods Ranging from 0.01 to 10 s, PEER 2013/06, Pacific Earthquake Engineering Research Center, Berkeley, California, USA, 2013.

CEN: Eurocode 8: Design of structures for earthquake resistance Part 5: Foundations, retaining structures and geotechnical aspects (EN 1998-5:2004), 2004.

Gailler, A., Hébert, H., Loevenbruck, A., and Hernandez, B.: Simulation systems for tsunami wave propagation forecasting within the French tsunami warning center, Nat. Hazards Earth Syst. Sci., 13, 2465-2482, https://doi.org/10.5194/nhess13-2465-2013, 2013.

García-Mayordomo, J.: Creación de un modelo de zonas sismogénicas para el cálculo del mapa de peligrosidad sísmica de España, Instituto edited by: Geológico y Minero de España, Madrid, 125 pp., available at: http://igmepublicaciones.blogspot.com.es/ 2014/10/riesgos-geologicosgeotecnia.html (last access: 1 March 2017), 2015.

García-Mayordomo, J., Insua-Arévalo, J. M., Martínez-Díaz, J. J., Jiménez-Díaz, A., Martín-Banda, R., Martín-Alfageme, S., Álvarez-Gómez, J. A., Rodríguez-Peces, M., Pérez-López, R., Rodríguez-Pascua, M. A., Masana, E., Perea, H., MartínGonzález, F., Giner-Robles, J., Nemser, E. S., Cabral, J., and the QAFI Compilers Working Group: The Quaternary Active Faults Database of Iberia (QAFI v.2.0), J. Iberian Geol., 38, 285-302, 2012a.

García-Mayordomo, J., Martínez-Díaz, J. J., Capote, R., MartínBanda, R., Insua-Arévalo, J. M., Álvarez-Gómez, J. A., Perea, H., González, Á., Lafuente, P., Martín-González, F., PérezLópez, R., Rodríguez-Pascua, M. A., Giner-Robles, J., Azañón, J. M., Masana, E., Moreno, X., Benito, B., Rivas, A., GasparEscribano, J. M., Cabañas, L., Vilanova, S., Fonseca, J., Nemser, E., and Baize, S.: Modelo de zonas sismogénicas para el cálculo de la peligrosidad sísmica en España, in: Proceedings of the VII Asamblea Hispano Portuguesa de Geodesia y Geofísica, 2328 June 2012, San Sebastián, Spain, 5 pp., 2012 b. 
García-Mayordomo, J., Insua-Arévalo, J. M., Martínez-Díaz, J. J., Martín-Alfageme, S., Jiménez-Díaz, A., Martín-Banda, R., Rodríguez-Escudero, E., Rodríguez-Peces, M. J., CabañasRodríguez, L., and Gaspar-Escribano, J. M.: Seismogenic faultsource characterization in SE Spain: Implications for probabilistic seismic hazard assessment, in: Proceedings of the XV World Conference on Earthquake Engineering, 24-28 September 2012, Lisbon, 2012c.

García-Mayordomo, J., Martín-Banda, R., Insua-Arévalo, J. M., Álvarez-Gómez, J. A., Cabañas, L., Cantavella, J. V., Crespo, M. J., Pereira Dias, R., Pascual, G., and Alfageme, S.: La base de datos de fallas activas cuaternarias de Iberia (QAFI v.2): características, aplicaciones y problemas, in: Proceedings of the VII Asamblea Hispano Portuguesa de Geodesia y Geofísica, 2328 June 2012, San Sebastián, Spain, 5 pp., 2012d.

Hanks, T. C. and Kanamori, H.: A moment magnitude scale, J. Geophys. Res., 84, 2348-2350, 1979.

IBERFAULT: Second Iberian Meeting on Active Faults and Paleoseismology, available at: http://www.iberfault.org/index.php/en/ (last access: April 2017), 2014.

IGME: QAFI v.3: Quaternary Active Faults Database of Iberia, available at: http://info.igme.es/qafi (last access: 1 March 2017), 2015.

IGME: MAGNA 50 - Mapa Geológico de España a escala 1:50.000 (2nd Serie), available at: http://info.igme. es/cartografiadigital/geologica/Magna50.aspx, last access: 1 March 2017.

IGME and ENRESA: Mapas Neotectónico y Sismotectónico de España a escala $1: 1.000 .000$, Vol. I, 237 pp. and Vol. II, 167 pp., available at: http://info.igme.es/qafi/Download.aspx/ (last access: 1 March 2017), 1998.

IGN-UPM: Actualización de Mapas de Peligrosidad Sísmica de España 2012, Centro Nacional de Información Geográfica, Madrid, 267 pp., 2013.

ITGE: Mapa Neotectónico, Sismotectónico y de Actividad de Fallas de la Región de Murcia a escalas $1: 200.000$ y $1: 100.000$, Memoria, 99 pp. and Annex V: Fichero de Fallas (Vol. I), 454 pp., available at: http://info.igme.es/qafi/Download.aspx/ (last access: 1 March 2017), 1991.
Martínez-Diaz, J. J., Masana, E., and Rodríguez-Pascua, M. A. (Eds.): Active Faults in Iberia, J. Iberian Geol., 38, 7-8, 2012. Michetti, A. M., Esposito, E., Guerrieri, L., Porfido, S., Serva, L., Tatevossian, R., Vittori, E., Audemard, F., Azuma, T., Clague, J., Comerci, V., Gurpinar, A., Mc Calpin, J., Mohammadioun, B., Morner, N. A., Ota, Y., and Roghozin, E.: Intensity Scale ESI 2007, in: Memorie Descrittive Carta Geologica d'Italia, 74, edited by: Guerrieri, L. and Vittori, E., Servizio Geologico d'Italia - Dipartimento Difesa del Suolo, APAT, Roma, 53 pp., 2007.

Rivas, A.: Contribución metodológica para incorporar fallas activas en la modelización de la fuente dirigida a estimaciones de peligrosidad sísmica. Aplicación al sur de España, $\mathrm{PhD}$ thesis, Universidad Politécnica de Madrid, Madrid, 235 pp., 2013.

Schwartz, D. P. and Coppersmith, K. J.: Fault behavior and characteristic earthquakes: examples from the Wasatch and San Andreas Fault Zones, J. Geophys. Res., 89, 5681-5698, 1984.

Simón, J. L.: Compresión y distensión alpinas en la Cadena Ibérica Oriental, PhD thesis, Instituto de Estudios Turolenses, Teruel, 269 pp., 1984.

Stirling, M., Rhoades, D., and Berryman, K.: Comparison of earthquake scaling relations derived from data of the instrumental and preinstrumental era, Bull. Seismol. Soc. Am., 92, 812-830, 2002.

Wells, D. L. and Coppersmith, K. J.: New empirical relationships among magnitude, rupture length, rupture width, rupture area, and surface displacement, Bull. Seismol. Soc. Am., 84, 974 1002, 1994.

Wesnousky, S. G.: Earthquakes, Quaternary faults, and seismic hazard in California, J. Geophys. Res., 91, 12587-12631, 1986.

Wesnousky, S. G.: The Gutenberg-Richter or the characteristic earthquake model, which is it?, Bull. Seismol. Soc. Am., 84, 1940-1959, 1994.

Youngs, R. R. and Coppersmith, K. J.: Implications of fault slip rates and earthquake recurrence models to probabilistic seismic hazard estimates, Bull. Seismol. Soc. Am., 75, 939-964, 1985. 